\title{
Classroom Management in Project Work
}

\author{
May Britt Postholm \\ Programme for Teacher Education, Norwegian University of Science and Technology, Trondheim, Norway \\ Email: may.britt.postholm@ntnu.no
}

Received 6 August 2015; accepted 16 November 2015; published 19 November 2015

Copyright (C) 2015 by author and Scientific Research Publishing Inc.

This work is licensed under the Creative Commons Attribution International License (CC BY).

http://creativecommons.org/licenses/by/4.0/

(c) () Open Access

\section{Abstract}

The article Classroom management in project work focuses on the project work method and the teacher's leader role in a lower secondary school. The main reason for focusing on this work method is that we must continuously learn and develop to keep up with societal developments. The article argues that education and training in school should enable and encourage pupils to use their curiosity and ask questions they want answers to, and in this way create a lifelong learning process when their formal schooling has come to an end. This leads to the project work method, which starts with a research question or problem formulation. The goal of teaching in lower secondary school in Norway is that it should be varied and practical, while the pupils should also experience it as relevant and challenging. The intention is that such a work form will increase pupil motivation and learning. The purpose of this article is to show how the project-work method may provide teaching that is varied, practical, relevant and challenging. Moreover, another aim is to highlight the teacher's role as the leader of pupil learning in project work. The article is based on a qualitative case study where the empirical findings have been analysed according to Dewey's and Vygotsky's theories and to theories on classroom management.

\section{Keywords}

Classroom Management, Teacher as Leader, Project Work, Qualitative Study

\section{Introduction}

The aim of work in school is that pupils should learn and develop. Modern society also requires that we are prepared to acquire knowledge throughout our lifetimes. Learning is a lifelong process. Thus knowledge is a perishable good, meaning that we need to be continuously learning and developing to keep up with developments in society. As active participants we can also contribute to the development of our society with our knowledge. Bearing this in mind, teaching in school should enable and encourage pupils to use their inherent curiosity, always asking questions they want to find answers to, thus being in a lifelong learning process after completing 
their formal schooling. There are a number of work methods that put pupils' curiosity into play. Exploratory work and problem-based teaching may serve as the point of departure for the pupils' activities. When considering teaching that aims to arouse pupils' curiosity, and hence their commitment, we come to the project-work method, which is initiated by formulating a problem or a research question.

Research shows that while there is a high level of pupil activity in school, pupils who are struggling may not find this motivating (Haug, 2012). Research also shows that there is little cooperation between pupils and also little contact between the teacher and his or her pupils. Haug states that research today advises variation in work forms because pupils profit from different learning strategies, and adds that we should not be satisfied with simply using the methods, but should also investigate in detail how these methods are used.

The aim of teaching in lower secondary school in Norway is that the teaching should be varied and practical, while the pupils should also experience the teaching as relevant and challenging (Norwegian Ministry of Education, 2011). The intention is to increase the pupils' motivation and learning. The purpose of this article is to show how the project-work method may make teaching varied, practical, relevant and challenging. Another aim of the article is to examine the teacher's role as leader of the pupils' learning in project activities. I will first present theory on classroom management. Then I will present Dewey's theoretical foundation for project work, as well as Vygotsky's theory to help us understand the processes in this work method. I will then describe a concrete project which I will analyse and discuss using the presented theory. The article will end with a summary reflection on the possibilities of project work in terms of pupil motivation, learning and development.

\section{Classroom Management}

According to Doyle (1986), classroom management has two purposes. First, it must establish a calm environment in the class so that pupils can take part in meaningful learning. Second, classroom management must contribute to developing pupils' social and moral competence. Thus, according to Doyle, classroom management means creating an environment that can contribute to the pupils' academic and social development. Teachers who establish an inclusive learning environment and who maintain calm and quiet that will help pupils in their work are good leaders, and thus also good teachers. This understanding means that the teacher as a leader contributes to steering the pupils into their learning activities, thus making it easier for each pupil to learn (Ogden, 2004). Ina social-constructivist perspective, classroom management is about creating a good learning environment and a community that appreciates learning (Prawat, 1996). This requires, according to Doyle (2006), a learning environment where the teacher creates peace and quiet for learning and contributes to the learning processes as a good guide. According to Friedman (2006), teachers may be challenged in their efforts to balance between creating orderliness for learning and guiding the pupils in their learning activities.

The school system and research are both interested in teachers as leaders of pupils and their learning activities. Research shows that good leadership is decisive for the pupils' learning outcome (Hattie, 2009; Nordenbo, Larsen, Tiftikci, Wendt, \& Østergaard, 2008). Understanding the class as a social system is a prerequisite for performing good classroom management. The pupils have different social and cultural backgrounds. They have different experiences of mastering and different expectations as to what school is to be for them and what they can contribute to their own learning and learning community. Doyle (2006) uses an ecological perspective when using six concepts to describe the classroom. It is: multidimensional-many things take place on different levels, simultaneous-many events occur at the same time, immediate-events change quickly, unpredictable-events may take unexpected turns, public-there are many spectators to the events and historical-classes often meet over an extended period of time, forming shared understandings, norms and routines that influence the progression of the class. Work with a class as a social system means an interchange between the individual factors and their mutual dynamics.

Doyle's six concepts (2006) describing the classroom and the activities are good descriptors for project work. The pupils normally work with various problem formulations and research questions and pursue the answers in different arenas in school and the local environment. The teacher as a leader must therefore be able to lead processes where much occurs quickly and at the same time, and also lead processes initiated by the pupils, thus dealing with the unknown. This type of work method challenges the teacher as leader to create a shared understanding of how to deal with each other and the academic work in the project. Hence, the teacher is challenged to create a good learning environment and to guide the pupils in their work to answer the research questions they have chosen. 
Leading a class thus means creating an environment which supports and facilitates for academic and social learning. This is supported by researchers (Evertson \& Weinstein, 2006; Wubbels, 2011), and according to Marzano (2009), a good classroom manager makes a difference for pupil learning outcomes by being alertly in attendance during the teaching. As the classroom manager, the teacher influences pupil learning outcomes directly and indirectly by impacting the learning environment, and the teacher may create an activity that is perceived as enough of a reward for the pupils (Reeve, 1996; Ryan \& Deci, 2000). The purpose of school is to develop free democratic individuals who are a benefit to themselves and others, but being able to lead oneself in the long term is, according to von Ottingen (2003), only possible through external influence or through one's upbringing. Eventually the pupils will be able to regard their own work and own learning process in ametacognitive way (Boekaerts, Pintrich, \& Zeidner, 2000; Flavell, 1976; Zimmerman, 2001, 2006). Classroom management thus refers to an asymmetric relationship between the pupil and the teacher, where over time the pupils will be drawn in and assigned more responsibility adapted to their age and development. This is not an equal relationship, but it should be balanced. The teacher must exercise a form of authority or maintain a certain degree of control, and must also ensure that curriculum objectives are being addressed and met, thus maintaining external responsibility (Juul \& Jensen, 2003). The teacher must also be supportive, approving and close to each pupil. When it comes to the understanding teachers have of their relationship to their pupils, Evertson and Weinstein's (2006) concept of the "warm demander" comes to mind. As teachers say, it is about having control while also showing approval, recognition and care.

According to Stensmoand Harder (2009), four fundamental premises or work tasks are essential for the teacher in providing good classroom management: 1) a positive, supportive relationship to each individual pupil; 2) the establishment of a good learning culture and learning community; 3) the establishment of structure, rules and routines, and 4) clear expectations and motivation of the pupils. Classroom management thus does not simply consist of individual factors, what is important is rather how the individual factors are used together. An integrated competence is required if a teacher is to be a good classroom manager.

\subsection{The Theoretical Foundation of Project Work}

In 1918, Dewey's student and friend William Heard Kilpatrick wrote an article he called "The Project Method". The idea he presents in this article is that pupils should manager themselves in their work, motivated by their commitment. Even if Kilpatrick was his student, Dewey expressed doubts about his ideas and thoughts on the project method and his unilateral focus on the pupil. Dewey attached importance to the teacher's role as supervisor and leader of the pupils' work. He believed it was the duty of the teacher to lead the pupils towards the goals of various group activities (Dewey, 1902, 1916, 1938). Dewey (1916) maintained that a democratic society rejects the principle of external authority, and that it should be replaced by voluntary commitment and interest. Dewey claimed that pupils should work on topics they are interested in, not just topics the teacher has instructed them to work on, and they should have the opportunity to practise reflective thinking. Below I will present some of the key ideas in Dewey's theory, as well as some of Vygotsky's thinking in this area to help us to understand the learning processes in the project method.

\subsection{Dewey's Theory}

The American philosopher and psychologist John Dewey (1859-1952) believed that it was important to see or envision the probable consequences of our actions and how these consequences may then impact us and thus our thinking (Dewey, 1916). Hence, it is important to create an environment that puts the activity in motion so that a person's thoughts can develop. But the activity in itself does not generate experience or change. "Learning by doing", or merely being active, is not enough for enabling learning. We may learn something new when we reflect on the changes that our actions or activities have led to. Dewey $(1916,1938)$ also wrote about the continuity of experiences. According to him, people are best prepared for the future when their learning is based on experiences in the present while bearing both the past and the future in mind. Dewey (1900) considered social activity to be a vital element in a person's development. He believed that certain capacities in a person would be activated by the stimulation of interacting with others, such as when working with others.

The term "interest" according to Dewey means that a person and the environment are in interaction with each other in a development situation. This term expresses a personal emotional commitment. Learning means to learn something from experience which will help a person to meet and deal with difficulties in future situations. 
Learning, which is a constant restructuring and reconstruction of experiences, occurs when young and old discover something which is new to them. This means that the knowledge which is construed is not necessarily unknown to others.

Dewey did not see learning goals as an individual result but believed that goals can give directions and frameworks that pupils may be active within. The pupils must be aware of and plan appropriate activities. According to Dewey, having a goal means acting in a way that will make meaning. He also believed that learning goals should be based on the interests and needs of the learners because all learning occurs for an individual in a particular place and a defined time. According to Dewey, learning goals must be established in the context of the activities the pupils are instructed in and which are in their own interests. Dewey maintained that educators must be sceptical of general goals given by the authorities without their own input, and that there must be interaction between the content/subject and the interests of the pupils (Dewey, 1916). With this as the point of departure, school activities and day-to-day activities can be connected. Dewey believed that school activities should be more closely related to life outside the classroom and added that resources are wasted if the school does not exploit the experiences the pupils have gained outside school. The pupils also lose the opportunity to apply what they had learnt in school in their day-to-day lives because school is isolated from life outside its walls (Dewey, 1938).

Dewey asserted that true teaching is created by experience paving the way for new experience, and that the teacher's most important duty is to create experiences leading to growth through activity in the local neighbourhood, as well as in the classroom (Dewey, 1916). Intellectual freedom will grow in pupils who have a question that awakens their curiosity, who can work under conditions that give them the opportunity to find the necessary information and who can use equipment that will draw them into the learning process through their interests (Dewey, 1938). Dewey $(1916,1938)$ claimed that the project method was a common activity for teachers and pupils. He attached importance to how the teacher should be a supervisor and a leader of the work. The teacher should guide the pupils towards goals created in a dialogue between the pupils' interests and curriculum objectives, and furthermore lead group activities, a common work form in the project method.

\subsection{Vygotsky's Theoretical Contribution}

Sociocultural theory expresses the thoughts and ideas of the Russian psychologist and philosopher Lev Semyonovich Vygotsky (1896-1934). Vygotsky maintained that learning occurs on two levels. Each function in a child's cultural development appears twice: first on a social level and later on an individual level. In other words: first between people (the intermental plane), and then within the child (the intramental plane) (Vygotsky, 1978: p. 57). Learning starts on a social level between individuals, and is then internalised or becomes part of each individual's knowledge or learning. In this learning process language is an important tool (Vygotsky, 1978, 2000). Vygotsky named three forms of dialogue. The first is a dialogue involving a conversation between at least two persons, external social speech. The second is an egocentric dialogue, where you talk out loud to yourself. The third is an internal dialogue where you are conducting a tacit conversation with yourself (Vygotsky, 1978, 2000).

Thus learning starts in a social community and then becomes a part of each individual participating in this community. This does not mean that all participants will develop the same, but developments will be connected to the development level each individual is on to start with. Vygotsky (1978) refers to this as the actual development level, i.e. what the pupils know or can do, and what they can demonstrate during a test, for example. He (1978) calls what is within the range of what pupils can learn "the zone of proximal development". This zone is described as the difference between what the pupil knows or can do alone, i.e. the actual development level, and what the pupil can manage to do or understand in interaction or dialogue with a more "competent other". This may be the teacher or another pupil. Hence, pupils working in a group should be within each other's development zones if they are all to progress in the learning process.

\subsection{The Context of the Study}

Before describing how I studied the project and the project's pathway in this class, I will give a short presentation of the class and the academic framework for the work as a context for the project.

Siri is the name I have given to the teacher in this class, which consists of 29 pupils, 13 girls and 16 boys. No pupils have special teaching during the project-work period, and Siri feels that the atmosphere and environment 
in the class are good. The classroom this class uses is quite full when all the pupils are in attendance. During the project period, group rooms and special rooms, such as natural science rooms and computer labs, are used when available. Some pupils will also be in the library or elsewhere obtaining information, so the classroom is not so densely populated during the entire project period.

The pupils' room is an ordinary classroom. It is square with a blackboard attached to one wall. The pupils' desks are normally placed facing the blackboard, but during the project period they are placed in groups. On the wall to the right of the pupils' desks there are storage shelves or boxes for them to use. The door into the room is also built into this wall. The wall to the left of the desks has windows offering a view of the schoolyard. The classroom is on the ground floor, as are all the classrooms in the school. On the wall opposite the blackboard space has been set aside to hang up pupils' work.

The project period observed stretches over five weeks, and the project is implemented in accordance with the school's local curriculum focusing on living together. The class has project teaching hours on the schedule all year. The three final classes on Wednesdays and the three first ones on Thursday are used for project work each week. This creates coherence in the work with different project pathways. The subjects included in this project were Norwegian, social studies, physical education, religion (now religious and ethical education) and natural science.

\subsection{The Method Used}

I conducted a case study (Creswell, 1998) of the project led by Siri. She had used the project-work method for several years in her teaching career, and she also had a reputation for being a good teacher. Therefore this teacher was chosen as an informant for the study. I observed all the 30 lessons and conducted semi-structured interviews (Kvale \& Brinkman, 2009) with the teacher before, during and after the project work. Before the project started I interviewed the teacher to get general information about the work that she was going to start, and information about the class. During the five weeks the project lasted I interviewed her every week on the basis of the observations I had made to encourage her to reflect on the processes and to understand them from her point of view, the emic perspective (Denzin \& Lincoln, 2000). In addition to interview data, the pupils' written evaluations of the project are included in the data material.

During the transcription work, which I did myself, I realised that the phases of the project (Berthelsen, Illeris, \& Poulsen, 1987) could serve as categories for the data material, and make it possible for me to report on the processes. The observations made it possible to describe the processes in depth and to include the teacher's and the pupils' utterances, thus making them thick descriptions (Geertz, 1973).

\subsection{Quality and Ethics}

To ensure the quality of the work I have used the member-checking approach (Lincoln \& Guba, 1985), meaning that the teacher has read the article and confirmed that she finds the descriptions of the project to be accurate accounts. The article complies with the ethical principle of making participants anonymous (NESH, 2006), and consequently the teacher has been given a fictitious name to avoid recognition.

The descriptions and experiences that have been presented are connected to one specific teacher. The findings presented may also have importance beyond their context if readers of this text can use it to think creatively and imaginatively (Geertz, 1973), thus using it as a thinking tool (Gudmundsdottir, 2001). This means that the findings can contribute to the development of classroom management and learning in other classrooms as well.

\subsection{Project Work in Practice}

Already in 1987 Berthelsen, Illeris and Poulsen wrote a book entitled "Introduction to project work" in which they claim that project work has eight phases, but that these phases are not to be seen as carved in stone. Below I will present the project I studied, which was carried out in Year 9 of lower secondary school, using the eightphases as the framework for the presentation.

\subsection{The Project Pathway in Siri's Class}

\subsubsection{Introduction}

Phase one of the project is the introduction. This phase aims to arouse motivation and to inform about the pro- 
ject work method itself. In this phase the external frameworks for the project pathway are also decided (Berthelsen et al., 1987).

Siri states that she has spoken with the pupils well before the launch of the project. She has done this to motivate them and to generate ideas for topics. She mentions the overarching theme to them for the first time two weeks before the start of the project. It is "Norway, a multicultural country". She then repeats it one week before they are to start. This phase has a dual purpose. It motivates the pupils, while also pointing out which literature the pupils may find useful. Siri believes that it is important to know something about what the pupils will be writing about so the library can order appropriate literature. This phase shows the direction the research questions and problem formulations may take, even if the pupils do not need to feel bound by the proposals they present in the introductory phase. The pupils choose topics to write about according to the overarching theme Siri has presented to them. In conversations with the pupils Siri discovers that she may have to change her suggested overarching theme, as they find it difficult. Siri therefore modifies it to "Norway, a country with many cultures and many groups of people.”The first part of the project which includes choice of topics and division of the pupils into groups thus comes after a motivation phase or introduction phase which Siri launches two weeks before the project starts.

\subsubsection{Choice of Topics}

In this phase the pupils are divided into project groups and choose the topics or issues their project will examine (Berthelsen et al., 1987).

On the first day of the project the pupils propose topics to work on. These are put on the blackboard, and the names of the pupils are entered under the topics they propose. Siri wants the pupils to form groups according to their interest. The process of dividing the pupils according to the topics is easy. The topics are: the Sami people, transvestites, lesbians, racism, circumcision, immigrants and Satanism. After the initial quick noting down of the topics on the board, seven pupil names are missing. When the teacher asks whether the pupils without a topic would like to choose one, they gradually find one to sign under. One pupil includes a co-pupil in his group by saying "Join us!" When class is over only two pupils do not have a group. Siri arranges a meeting with these two, and the outcome is that a group of five wanting to work on a topic is split into two so that the two pupils without a topic join a group of three and a group of four, respectively.

\subsubsection{Planning}

This is the phase where the project groups undertake the practical planning of the project. This refers to scheduling, work organisation and distribution, the choice of literature sources and other technical aids (Berthelsen et al., 1987).

After all the pupils have been assigned a group, Siri distributes a timeline and a project folder to each pupil. The pupils can keep their papers in the project folder throughout the project. The pupils can use the timeline to structure their work and to have an overview of the working hours at their disposal. Siri explains why she gives the pupils a timeline in the following way:

It's to raise their awareness of what is waiting for them around the next bend, simply. I have experience of this work, and we adults know that when we start a project, we initially think we have all the time in the world, and then we coast a bit. This is why we start at the bottom when we review the timeline, and work our way up. I have very good experience in this area. And when we introduce something that we have used a lot, it's like an almost finished item. At this point I have conversations with the pupils to prepare their project for the presentation.

The pupils spend the rest of this project session deciding the research question for the topic they have chosen. Towards the end of this session Siri reviews with all the groups together to hear what they have planned in relation to the topics they have decided. Siri also makes each group consider their topic in relation to the overarching project theme.

In the planning phase, when the pupils divide up work tasks, Siri states that it is difficult to maintain an overview of what is going on. She says:

I actually know too little about this process and what is going on then, for so much is happening, and there are 29 of them, and there's no way I can follow up everything. In groups where you have pupils who are 
relatively weak, the co-pupils are good at distributing work because they know each other very well. They are good at distributing and giving those who are not so clever more practical tasks.

Siri knows that weak pupils are assigned more practical tasks, but is uncertain about what occurs in this process leading to the division of work.

\subsubsection{Problem Formulation/Research Question}

During this phase each project group will define and instantiate their problem by preparing one or more problem formulations or research questions (Berthelsen et al., 1987).

In the next project session Siri puts the overarching theme on the board. A pupil from each group puts the research question for the various topics below it. Siri approves all the research questions that are put on the board. The final questions prepared by the groups are: 1) What is the mental state of a transvestite? 2) What is Satanism and the Church of Satan? 3) What is it like to be an immigrant? 4) What is male and female circumcision, and how is it done? 5) What does a witch do? 6) What are transvestites? 7) What is a Sami? 8) What is Nazism? 9) Lesbians, which culture do they have?

After all the questions have been put on the board, but before the pupils continue their group work, Siri reminds them about the assessment form for the presentation of the project. The form has a number of checkpoints the teacher will use to assess the presentation. The first checkpoint refers to whether the groups have answered their question and the content of the presentation. Moreover, the pronunciation of words is assessed, including words in English. Verbal speech is important, i.e. whether everything is pronounced clearly and whether the sound level is adequate. The use of technical aids such as projectors, the blackboard, CDs, video, television and so on is also a checkpoint on Siri's assessment form. Importance is also attached to variation during the presentation, that it is read, that something is displayed and that things are said without relying on a manuscript. Contact with the audience is also important. Siri will notice whether the pupils ask questions and explain things to their co-pupils. Group cooperation is also assessed during the presentation. Siri will also comment on the general impression of the presentation. She puts the assessment form on the notice board in the classroom.

Before the pupils start in their groups, Siri reminds them to come together during the last 15 minutes of the session to write a journal. They have to do this after each project session. This journal, called the day report by the class, should describe what the pupils have done and their plans for the next session. Finally, they should assess their own work session.

\subsubsection{The Implementation Phase}

During this phase the groups endeavour to realise the plans and goals they have setand attempt to find answers to the questions they have chosen by obtaining and processing information (Berthelsen et al., 1987).

At the start of all the project sessions the class sits together to clarify any questions and so Siri can inform them about which groups she wants to talk to. Siri also puts two flip-over sheets on the board, saying IT and library at the top. The pupils write their names there if they need to search for information in these locations. Siri explains why she uses these sheets:

We have used this ever since we have been working with projects, and this strategy has stuck because it has become an innate social habit for them. But when we started with projects, I was very careful and had them making agreements for everything they were doing, so I would have control over where they were, and they needed permits to go certain places. I realise this making agreements is a very important social skill to have. So they are quite used to doing this, writing down where they are, and where they are going.

Siri started with two social sub-goals in the class: "Listen to each other" and "Everyone is part of it". She does not remind the pupils about these goals when the project starts as she would first like to see if there are pupils who need support to manage this. But it turns out during the project that the pupils in one group have difficulties dividing up the work, and Siri eventually needs to remind them that they all have to take part in the work. She asks the group to sit down and agree on what each of them should do. They also have to write down the division of work they decide on.

Siri calls it a "resting point" when the pupils have to sit down to cooperate on work tasks. Dividing up work in groups is one such resting point. When the end of the project work period is approaching and the groups are preparing for their presentations, Siri has introduced a resting point she calls "the almost finished point". Then 
the pupils have to consider what material they have and if they have enough. They must also determine whether each member has carried out his or her task. At this point in the process Siri has a mentoring dialogue with each of the groups. Each group gets an appointed time they can prepare for. Siri wants to know how the pupils have structured their presentation and how they are planning to present it. She also asks the pupils how they would like to be assessed by the other pupils, whether they intend to hand out a form or ask the class open questions. The groups are also asked how they plan to determine how much the others have learnt from the presented material. Together Siri and the pupils agree that both questions and a questionnaire should be used. Siri also wants to know whether there have been any cooperation problems in the group during their work, or whether things have functioned well. One of the groups proposes that they want to talk about how they collected information and the project's pathway. Siri also wants the groups to determine how long it will take to present their projects.

Siri conducts both mentoring dialogues and mentoring meetings with the pupils during the project work. During a dialogue various issues are raised even if the group has not encountered particular problems during the work process. Siri has this dialogue with all the groups several times during the implementation phase of the project. When there is a problem in a group, the pupils have a meeting with Siri. Siri and the pupil groups can take the initiative to call such meetings.

During the work sessions Siri hears comments the pupils have exchanged in the groups. Siri notes them and reads out these "nuggets" as she calls them at the end of each project session. Here is a selection:

“How nice, you're making it work!" "What do we do now?" "We really have many good symbols now." "I have a proposal for a question" "I'm really looking forward to the presentation" "Look here, we have loads of stuff now, don't we!" "This is going to be so good!" "The people we have to call have an unregistered telephone number." "I want an individual grade, one group member hasn’t done anything, really!"

During the final 15 minutes of the project session the pupils write their journal. The pupils' work ends in a product or presentation.

\subsubsection{Making a Product}

During this phase a product is prepared to make the work available to others. This may be a written report, an exhibition, a film or slides, a newspaper article or a meeting (Berthelsen et al., 1987).

After each group has determined how long their presentation will take, the class together with Siri agrees on a schedule for the presentations. Each group receives a time slot for their presentation. Siri puts this time schedule for the pupils on the board. She wants the pupils to use a manuscript or "shooting script" in the presentation. She explains these terms as follows:

In this project the pupils have been told that they will be making a verbal presentation, and that then we will use a shooting script or manuscript. A shooting script consists of small steps, and they have to remember inside the small steps, or you have to have keywords to manage. I attach importance to this because I feel that school assigns far too much importance to written activities. I appreciate verbal, perhaps more creative and inventive presentations.

During the presentation the classroom is completely silent and the pupils pay close attention to what is going on up by the board. Each group writes their question on the board before starting. The pupils use various technical aids and special effects to present their findings. One of the pupils in Group 1 (see previous descriptions of questions) has dressed up as a transvestite. Group 2 softens the ceiling lamps and lights candles on the teacher's desk. They start with examples of Satanist music, and later in their presentation they show how spiritism is performed. During Group 4's presentation a witch hangs from the ceiling. This group also uses mood music and poetry reading to present their answer. The pupils have also lit incense in the classroom. Group 7 shows slides of Sami people. All the groups use various aids such as the projector, board, placards, film and pictures to vary their presentations. Some have also made drawings. Group 3 has invited an immigrant to talk about how it is to live in Norway. This group also serves a foreign dish in connection with their presentation.

After the presentation some of the groups hand out questionnaires so they can determine how much of the presentation the other pupils have understood and remember. The groups also ask the pupils directly whether they have any questions about what they have been listening to, watching and experiencing. Some have prepared forms for the other pupils to use for their assessments. The pupils also assess each other immediately after each group presentation. It is obvious that the pupils apply the presentation criteria when commenting on each other's 
performances. They say:

"Much material”. "Nice with a film.” "Learnt a lot." "Spoke clearly.” "Good you opened with facts.” "Well done even if one member was absent." "Good use of voices." "Much good material, learnt much." "Good, cassette, candles, scent, good mood." "Good contact, but perhaps too much reading." "Good atmosphere, not boring." "Good voices." "Good you demonstrated differences between transvestites and transsexuals."

They also received comments on what could have been better:

"Could have spoken louder.” "Difficult to understand, quite vague material.” "Perhaps a bit too much.” "Don’t read as much.” "Don't keep doing other things while you're talking." "Might perhaps have practised the last text a bit more." "Look up more when you're reading." "Raise your eyes from the paper."

The pupils were also asked by the teacher what they thought about their presentation. Some of the answers were:

"We should have practised more." "We felt it was good, really."

Siri also offers some comments along the way, but she says they will also receive comments from her after all the project presentations have been made.

\subsubsection{Product Assessment}

In this phase the product is presented and assessed by the group and the other pupils and the teacher (Berthelsen et al., 1987).

Siri has a number of goals for the project. In the planning document prior to the project launch she states that one of the goals is to acquire knowledge. She wants the pupils to consider their own attitudes to groups and other cultures in Norway based on this acquired knowledge. Another goal is that the pupils should train in the project-work method and be inductive in their learning. Siri has also set the goal that she would like to sharpen the pupils' curiosity and inquisitiveness. Training in social skills is another goal of the project work. Siri gives the pupils a written individual assessment after the project. She assesses the pupils' achievements while she gives a total grade for the project work carried out. She also considers the pupils' journals when making her assessments. During the project she has also written a journal, noting thoughts about the work processes in the groups. A new element in this project is that she sets grades in the different subjects covered by the overarching theme, and based on the overall grade.

\subsubsection{Post-Project Work}

This is the phase where the group sums up its experiences and its learning outcomes, possibly correcting the product, undertaking generalisations relating to other fields and clarifying possible consequences (Berthelsen et al., 1987).

After the project Siri tells the pupils to assess the process they have gone through, based on written questions she gives them. Siri asked the pupils the following questions: 1) How did you like the division into groups? 2) How can we find out whether the others have learnt something from your research question? 3) Do you have any tips for the teacher/supervisor? The pupils generally appreciate being allowed to choose their groups, but six of them would like Siri to compose the groups. In his assessment, one boy writes that he would like to have girls in the group. Another pupil also feels it may be difficult for a pupil who is academically poor or socially inept. This pupil feels that in such situations Siri should help the pupil's way into a group.

In terms of choosing a topic, they all agree it was good that they were allowed to choose. One pupil writes "We're more focused on the material when we're allowed to choose." Another pupil states: "It's not possible to sneak out of the work when you have been allowed to choose the topic." Relating to the second question, the pupils have a number of proposals. They could consider having a survey or a small test. Some mention question forms, a questionnaire or a sheet of paper to write down what they have learnt. Some propose a sheet of paper with answers to be filled in or statements to be assessed as true or false. Some propose verbal questions asked in class. Another pupil feels that verbal questions should be asked in class after each project.

As to tips for the teacher, Siri receives feedback that the pupils have enjoyed the project process. "It was great fun.” One pupil feels that Siri should spend more time with the groups even if they have enough material. Another pupil would like the next project to be a drama project. Another pupil writes that they should discuss 
whether to sit alone or in groups the next time. Another pupil would like to sit in pairs and work on a topic they choose and in the end submit something in writing.

\subsection{Classroom Management and the Project Method: Analysis and Discussion}

Siri allows the pupils in her class to join in deciding what they are to work with in the project as a way of motivating them. This means that the work and the activity may in themselves be sufficient reward (Reeve, 1996; Ryan \& Deci, 2000). The teacher adapts the overarching theme so the pupils' proposalsfit. This allows the pupils to work with what they are interested in, which Dewey (1916) found important, and the topics the pupils are working on may also be perceived by them as relevant. In this way day-to-day activities will be connected to the school activity, both in terms of what the pupils want to learn more about, and in the implementation phase where they collect information in various arenas, including arenas outside school. The proposals for topics in this project might raise a few eyebrows; are the pupils trying to provoke the teacher? They propose topics which many people, particularly adults, may find offensive and if that is the case perhaps they should not be the focus of a learning process. Siri, however, takes the pupils' proposals seriously, and it is clear that the pupils do not rattle her confidence in any way. The pupils do not cross the border of what the teacher feels is her inner responsibility, her boundaries, needs, emotions and goals. Rather the opposite is true; she expands the framework for the project, clearly finding that the topics fit in the local curriculum and that she thus complies with the external responsibility (Juul \& Jensen, 2003).

Siri perceives the atmosphere and environment in the class as good, and she therefore allows the pupils to assume responsibility for forming interest groups. After completion of the project, Siri reflects on this phase. She realises that the teacher's role as the leader is a key element in the group establishment phase, even if the class environment is perceived as good. This is also found in the pupils' statements after the project. Some pupils may feel they are not wanted in a group, or perhaps they do not take any initiative to establish a group. Thus some may experience being left outside the community if the teacher does not lead such processes. To create a good learning situation, based on Vygotsky's (1978) theory, it is vital for the pupils' learning that they can sit in groups where they sense they are in mutual zones of proximal development. Friendships and relation ships may also take precedence over the choice of interest and for this reason the teacher should also be the active leader in putting together groups. By balancing friendship and interests, the teacher may contribute to motivating the pupils to find answers to their questions, thus forming a pupil community that appreciates learning. In social constructivist perspectives, such as those represented by Dewey and Vygotsky, importance is attached to how learning should take place in various communities of practice, and that one will be motivated by being a member of a community that appreciates learning. Learning is understood as development of understanding and meaning in interaction between the person and the environment he/she lives and acts in (Prawat, 1996).

In the groups, the pupils are allowed to work together. They plan work, carry it out and discuss the activity. Thus language contributes to pupil learning in the groups (Dewey, 1900; Vygotsky, 1978, 2000). The requirements and expectations the teacher has for the group activity will form the framework for it and may also influence the content of the pupildialogues. Siri has a clear rule that the pupils must inform her about where they intend to go to obtain information, and she states that this has become a social skill, thus also a routine. Siri also has expectations as to how they should structure the work in the groups. They must listen to each other and take part in the work. She also builds structures for the pupils by giving them a time line with "resting points", for example distributing the work and making a summary prior to the project presentation (the almost finished point). Siri also has clear thoughts about how conversations between her and the pupils may take place to help them progress in their work. She calls these conversations dialogues and meetings. She wants to have on-going dialogues with the pupils to maintain an overview of their group work in terms of process and content. Prior to meetings a problem may have arisen or a problem may be imminent. To put her finger on any problems that may be developing Siri must be alertly present in her practice (Marzano, 2009). She also lets the pupils call such meetings when they feel a need for it. Thus the pupils are given the primary responsibility for the work process, and they therefore are assisted. This means that over time they can lead themselves (von Ottingen, 2003) by having a meta-perspective on their own work (Boekaerts et al., 2000; Flavell, 1976; Zimmerman, 2001, 2006). As the leader of the project work Siri has created a shared understanding in the class of meeting points that represent norms and routines in the implementation of the project. These norms and routines clearly help her as the leader to deal with the complexity in the class during the project work (Doyle, 2006). 
Siri states that the pupils are good at distributing tasks in the groups, and the weaker pupils often are given practical tasks, such as making illustrations for the written work. It is obvious during the presentations that many practical tasks have been carried out, and that this helps to create variation in the presentations. Each person has contributed to the product, and they have all taken part in or at least listened to discussions in the groups. According to Vygotsky (1978), learning starts in a social community before becoming part of each person participating in the community. The development occurring in each pupil will be connected to the development level the pupil is on to start with. This means that everybody has the opportunity to learn in group work. But the teacher has a huge task if Vygotsky's (1978) theory of the zone of proximal development is to be used to determine how to compose groups. This means that the pupils must be on a level within each other's zone of proximal development. Based on pupil statements it may appear as if some of the pupils are not quite happy with the composition of the groups. After the project, Siri reflects on the important role the teacher has as the leader during the group establishment phases in a class, even when the environment is perceived as good. This does not only refer to the fact that the groups should function well socially, but that all group members should be in a community that contributes to learning for all participants (Hattie, 2009; Nordenbo et al., 2008).

Siri has a strategy for capturing conversations and utterances in the groups when the work is in process. She notes things down continuously in her observation journal as she moves around the classroom listening to what is being said. She will write down some of these utterances, calling them "nuggets" from the work session. The pupils are familiar with her strategy and listen attentively when Siri reads from her book. Thus the pupils are aware that they are being observed and seen. Siri's strategy may thus have a dual purpose. On the one hand, her observations may seem like supervision, and on the other hand, they remind the pupils that they are being seen and heard. As a leader we can call Siri a "warm demander", which is the precise description of teachers who supervise, have control and are also supportive by being approving and caring (Evertson \& Weinstein, 2006; Wubbels, 2011).

Siri has developed a strategy which she uses in her teaching. She also has a requirement she places on the pupils' presentations as they have to use a shooting script as part of their strategy. This can be called a learning strategy, as the use of written keywords helps the pupils to remember what to say. However, in most presentations the pupils lack a meta-perspective on the process and their own learning, and the established criteria for the presentation do not demand that the pupils should have this meta-perspective and in this way monitor their own learning (Boekaerts et al., 20000; Flavell, 1976; Zimmerman, 2001, 2006). But the pupils have many proposals for determining whether the others have learnt something from the presentation, and some groups also let the other pupils assess them in writing using a questionnaire they have prepared. They also give each other assessments after each presentation, and it is clear that the criteria help them in this assessment.

As Siri wants insight into what occurs between and within the pupils, she allows them 15 minutes to write a journal after each work session. They describe what they have done and what they plan to do in the next session, and also assess the current work session. However, they do not say much about what they have learnt. If the teacher had made them answer the question "What have I learnt?" after each work session, the focus might have been more on learning and not so unilaterally on actions in the process. The post-project work shows that the pupils have many good proposals for showing what they have learnt. Their level of involvement shows that they feel they are being heard. The utterances coming to light after the project signal that the pupils feel they are co-responsible when they take part in deciding the topic they are to work on.

\section{Conclusion}

Project work may be a work method that provides variation when used in conjunction with other work forms a teacher uses in the classroom. The project method also allows room for much variation in itself, as exemplified by the project presented in this article. This project work also shows that pupils are able to work practically, and that this way of working may be found both relevant and challenging. If the project-work method is to have this function, heavy demands are placed on the teacher as a leader.

Bearing in mind that the point of departure is a problem formulation or a research question, project work can be motivating in itself. The pupils may explore areas they are curious about and where they want to know more. This is a good starting point for learning. It is also the teacher's duty to help the pupils achieve goals laid down in the curriculum in force. The teacher's task as the leader will be to maintain the pupils' motivation in the interaction between the subject-content requirements and their interests. If a project is to function as intended, the 
teacher must also explain her expectations to the pupils, which must then be built into structures, rules and routines and into the relationships between the teacher and pupils and between pupils. Siri had a clear rule that the pupils at all times must inform her about where they intend to work, which also became routine for the pupils. She also had a clear structure for how the pupils were to be guided and helped in the process, and she also expected them to take the initiative to ask for and obtain help. She also signalled expectations to the pupils by observing them, and she showed them that she was doing this keenly by sharing "nuggets" with them. By concluding the sessions in this way she showed that she saw the pupils, and she was able to maintain a good relationship with them. Using verbal and written communication, such as the pupils' journals, the teacher also maintained good relationships and a good learning environment.

The description and analysis of the project presented here show that such a work form places high demands on the teacher as a leader if it is to function as intended. If the teacher has appropriate classroom management, meaning a positive and supportive relationship with each pupil, establishes a good learning culture and learning community, and establishes structures, rules and routines and clear expectations for the pupils, such a work form may promote pupil motivation and their academic and social development.

\section{References}

Berthelsen, J., Illeris, K., \& Poulsen, S. C. (1987). Innføringiprosjektarbeid. [Introduction to Project Work] Oslo: Forlaget Fag ogKultur A/S.

Boekaerts, M., Pintrich, P., \& Zeidner, M. (2000). Self-Regulation: An Introductory Review. In M. Boekarts, P. R. Pintrich, \& M. Zeidner (Eds.), Handbook of Self-Regulation (pp. 1-9). San Diego, CA: Academic Press. http://dx.doi.org/10.1016/B978-012109890-2/50030-5

Creswell, J. W. (1998). Qualitative Inquiry and Research Design. Choosing among Five Traditions. Thousand Oaks: Sage Publications, Inc.

Denzin, N. D., \& Lincoln, Y. S. (2000). Introduction. In N. K. Denzin, \& Y. S. Lincoln, (Eds.), Handbook of Qualitative Research (pp. 1-28). Thousand Oaks: Sage Publications, Inc.

Dewey, J. (1900). The School and Society. Chicago: The University Chicago Press.

Dewey, J. (1916). Democracy and Education. An Introduction to the Philosophy of Education. New York: Macmillan Company.

Dewey, J. (1938). Experience and Education. New York: Macmillan Company.

Doyle, W. (1986). Classroom Organization and Management. In M. C. Wittrock (Ed.), Handbook on Research on Teaching (3rd ed., pp. 392-431). London: MacMillan Publishing Company.

Doyle, W. (2006). Ecological Management to Classroom Management. In C. M. Evertson, \& C. S. Weinstein (Eds.), Handbook of Classroom Management: Research, Practice, and Competence Issues (pp. 97-125). Mahwah: Lawrence Erlbaum Associated.

Evertson, C. M., \& Weinstein, C. S. (2006). Classroom Management as a Field of Inquiry. In C. M. Evertson, \& C. S. Weinstein (Eds.), Handbook of Classroom Management: Research, Practice, and Competence Issues (pp. 3-15). Mahwah: Lawrence Erlbaum Associated.

Flavell, J. H. (1976). Metacognitive Aspects of Problem Solving. In L. B. Resnick (Ed.), The Nature of Intelligence (pp. 231235). Hillsdale, NJ: Earlbaum.

Friedman, I. A. (2006). Classroom Management and Teacher Stress and Burnout. In C. Evertson, \& C. Weinstein (Eds.), The Handbook of Classroom Management (pp. 925-944). Mahwah, NL: Lawrence Erlbaum Associated.

Geertz, C. (1973). The Interpretation of Cultures. New York: Basic Books.

Gudmundsdottir, S. (2001). Narrative Research in School Practice. In V. Richardson (Ed.), Fourth Handbook for Research on Teaching (pp. 226-240). New York: Macmillan.

Hattie, J. (2009). Visible Learning-A Synthesis of over 800 Meta-Analyses Relating to Achievement. New York: Routledge.

Haug, P. (2012). Aktivitetene i klasseromma. [Activities in the Classroom]. In P. Haug (Ed.), Kvalitetiopplceringa [Quality in Education] (pp. 58-76). Oslo: Det Norske Samlaget.

Juul, J., \& Jensen, H. (2003). Fra lydighettilansvarlighet-Pedagogiskrelasjonskompetanse. [From Obedience to Responsibility]. Oslo: Pedagogisk forum.

Kilpatrick, W. H. (1918). The Project Method: The Use of the Purposeful Act in the Education Process. Teachers College Record, 19, 319-335.

Kvale, S., \& Brinkmann, S. (2009). Det kvalitative forskningsintervju. [The Qualitative Research Interview]. Oslo: Gyldendal Akademisk. 
Lincoln, Y. S., \& Guba, E. G. (1985). Naturalistic Inquiry. Beverly Hills, CA: Sage Publications, Inc.

Marzano, R. (2009). Classroom Management That Works-Research Based Strategies for Every Teacher. New Jersey: Pearson Education Inc.

NESH (2006). Forskningsetiskeretningslinjer for samfunnsvitenskap, jus oghumaniora [Research Ethical Guidelines for Social Science, Law and the Humanities]. Oslo: Norwegian National Committees for Research Ethics. http://www. etikkom. no/no/Vart-arbeid/Hvem-er-vi/Komite-for-samfunnsvitenskap-og-humaniora/

Nordenbo, S. E., Larsen, M. S., Tiftikci, N., Wendt, R. E., \& Østergaard, S., Ministry of Education and Research (2008). Lererkompetanser og elevers laring i barnehage og skole. Et systematisk review utført for Kunnskapsdepartementet. [Teacher Competence and Pupils' Learning in Day Care and School. A Systematic Review by the Ministry of Education and Research]. Oslo (2nd Printing) [Copenhagen] Danmarkspædagodiske Universitetsforlagand Dansk Clearinghouse for uddannelsesforskning.

Ogden, T. (2004). Kvalitetsskolen. [The Quality School]. Oslo: Gyldendal Akademisk.

Prawat, R. S. (1996). Constructivisms, Modern and Postmodern. Educational Psychologist, 31, 191-206. http://dx.doi.org/10.1080/00461520.1996.9653268

Reeve, J, (1996). Motivating Others: Nurturing Inner Motivational Resources. Boston: Allyn \& Bacon.

Ryan, R. M., \& Deci, E. L. (2000). Intrinsic and Extrinsic Motivation: Classic Differences and New Directions. Contemporary Educational Psychology, 25, 54-67. http://dx.doi.org/10.1006/ceps.1999.1020

Stensmo, C., \& Harder, J. (2009). Lederstiliklassevcrelset-Innovation ogprofessionalitet. [Leadership Style in the ClassroomInnovation and Professionalism]. Fredrikshavn: Dafoloforlag.

Von Ottingen, A. (2003). Det predagogiske paradoks. [The Pedagogic Paradox]. Copenhagen: Klim forlag.

Vygotsky, L. S. (1978). Mind in Society. The Development of Higher Psychological Processes. Cambridge: Harvard University Press.

Vygotsky, L. S. (2000). Thought and Language. Cambridge, MA: MIT Press.

Wubbels, T. (2011). An International Perspective on Classroom Management: What Should Prospective Teachers Learn? Teaching Education, 22, 113-131. http://dx.doi.org/10.1080/10476210.2011.567838

Zimmerman, B. J. (2001). Theories of Self-Regulated Learning and Academic Achievement. In B. J. Zimmerman, \& D. Schunk (Eds.), Self-Regulated Learning and Academic Achievement: Theory, Research, and Practice (pp. 1-25). New York: Springer-Verlag.

Zimmerman, B. J. (2006). Development and Adaption of Expertise: The Role of Self-Regulatory Processes and Beliefs. In K. A. Ericsson, N. Charness, P. J. Feltovich, \& R. R. Hoffman, (Eds.), The Cambridge Handbook of Expertise and Expert Performance (pp. 705-722). Cambridge: Cambridge University Press. http://dx.doi.org/10.1017/CBO9780511816796.039 